REmarks. This case will doubtless be of interest to 1 engaged in "the great Tobacco Controversy." To those argue against the use of this luxury from its abuse it wil sent a tolerably well marked instance (better marked believe, than most which have been alleged on that sid the ill effects which sometimes occur from excessive smo The purely local character of the affection-for the patie fine healthy sailor, presented, notwithstanding his acute $s$ ings, no evidence of constitutional disturbance-left no of its origin in the local irritant of which he had made so use, and the success of the treatment directed to it confin this idea. The use of mercury was indicated by the gres duration of the part, and the combination of opium and $t$. emetic was useful in allaying vascular action and subduin extreme pain. Without trenching upon the domain of $t$ whose "mission" it may be to conduct this "controversy would only desire them to bear in mind the old adage, " tollit abusus usum."

\section{Briginal Communitations.}

\section{CASE OF PROLONGED RETENTION OF T? PLACENTA AFTER ABORTION.}

By Joun Roulston, M.D., Low Harrogate, Yorkshire.

Mrs. W., a robust woman, aged 41 years, having been married, but without family, sent an urgent message fo: to visit her on November 10th, 1856. I went immedia and found her suffering from profuse uterine hæmorr which had arisen in this wise. She was pregnant, thou this fact she had no suspicion; and on November 8th, she been attacked by severe abdominal pains, which she attrib to colic or commencing diarrhœa, and for the relief of she took tincture of rhubarb. After making frequent visi the water-closet, and using considerable expulsive effor fœtus (which, from the description, I should judge to been of about the fourth month) fell suddenly upon the snapping asunder the funis at the same time. A neigl ran in on hearing her cries of alarm, and, finding there wa hæmorrhage nor yet pain, told her that medical aid was $u$ cessary, as the afterbirth would soon come if she continu move about, which she accordingly did, hut without effect.

Two days after this event, on my arrival, I found that morrhage had been going on for some hours. She was in the clothes were saturated with fluid blood, and the char utensil was half full of coagula. There was considerable $f$ ness, and the flow was now abated in some degree. On amination per vaginam, I could barely reach the os uteri the finger; and, in consequence of the contracted state of $p$ which existed, as well as the rigidity of the soft parts, I f it impossible to introduce the hand. The cervix uteri appe flaccid, and the os merely admitted the tip of the finge could thus gain no decisive evidence of the contents of womb; and my patient was unable to say whether the plac or only coagula had been expelled previous to her retirin bed. There was no perceptible uterine action; I there carefully applied the tampon, put on a well adjusted ban and compress over the abdomen, and administered alter doses of infusion of roses with gallic acid, and ergot os every three hours. By these means the hæmorrhage arrested, but there was not any pain produced. I disconti the ergot at the end of four days; and the lochia ha ceased, I gradually allowed my patient to resume the position, and return to her avocations, paying her an occas visit, until November 26th, when sho expressed herself fectly well, and I discontinued my attendance. The qua of ergot given was two ounces.

December 22nd. Mrs. W. was again seized with floodin an alarming extent; and $I$ found her on the bed pale and $f$, with fluttering pulse, and covered with clammy perspira On making a vaginal examination, and clearing out the cos which filled that canal, I found the placenta just protrue through the os uteri, and by means of a little manipula with a curved probe, I was enabled to remove it. It $\mathrm{c}$. away without force in two portions, condensed into 8 fleshy substance, and presenting no sign of putrefaction; had there ever been the least offensive odour during the gress of the case. The hæmorrhage immediately subsided, there was no relapse, the recovery being very rapid.
The period of time which elapsed between the expulsion of the foetus and the removal of the placenta was forty-four days.

Remarks. I am induced to report this case as an example of the state of inertia the uterus may maintain for a length of time when containing a foreign boly, the slight constitutional disturbance, and the absence of putiidity. The fact of her having gone to the water-closet several times after the birth of the foctus, and being conscious of one or two substances passing per vaginam, together with the circumstances detailed, and the failure of all the means used to excite uterine action, rendered an expectant treatment the only resource.

\section{LECTURE ON MORAL INSANITY.}

By Jонк KIтснгкG, Esq., Medical Superintendent of the Retreat, near York.

[Continued from page 336.$]$

THERE is another mode in which original differences of mind are exhibited, to which I must devote a few sentences before passing to the consideration of the results from the foregoing principles to which it has been my great object to lead you. This is the singular and striking difference in the sensibility to impressions, or in the emotions with which different individuals are affected. The varieties of temperament are considered to afford some explanation of these phenomena. But there is something more than temperament concerned in them, because the same peculiarity attaches to all the temperaments. The violence, excitability, or mobility of the emotions, are, to a great extent, irrespective of temperament.

But we will leave temperament out of the question, and simply attend to the fact of the great difference we may observe in men with regard to their emotions. We observe that one man is excited to tears and intense sympathy by a tale of distress, whilst another is scarcely moved at all. An appeal to one man's feelings succeeds in stirring up an active exertion for the relief of want, which leaves the other in the enjoyment of cool and dispassionate indifference. A humorous story or incident moves one to violent laughter, whilst another, still capable of thoroughly enjoying it, does not stir a muscle of his face. An insult stings one to the quick which scarcely rouses another from his equanimity. I have read somewhere of a person who died in his chair from the chagrin of being called a liar. At the enunciation of the insult, he turned pale, simply uttered the words, "He called me a liar", and died. Dr. Aiken mentions a respectable foreigner, who, being once laughed at on some trifling account, was so much hurt and humiliated, that ever afterwards he was fully persuaded that all the ballad singers in the streets were engaged in turning him into ridicule; and when their songs were purchased and brought to him by his companions, in order to convince him of his mistake, he eluded the force of the evidence by saying, that what they sold was not what they sung. In other points, no man could talk or behave more rationally. In the same way, we may trace through all the modes in which feelings are called into action as much difference in their vividness and intensity, as we can perceive in the power of any other mental attributes. Men under the same circumstances of suffering or of pleasure, manifest their feelings in the most diverse degrees. The restraints of education impose a decorous self-control upon the expression of the ernotion; but, independently of these, the natival differences in the vividness and excitability with which we are impressed, break out, and assert the inherent differences that exist in our mental constitution in this respect.

Children, however, afford the best field for studying these original differences of mental constitution, both because they are less changed and modified by the effects of education, and because they are less influenced by the operation of the intellect and the will, in the expression of their emotions. Let a father announce to a family of children that he has some unexpected pleasure prepared for them, and watch the effect of the communication upon each. Whilst one claps his hands and loudly exults in the exuberance of his joy, another, with quiet gravity, prepares himself for the enjoyment, as for an ordinary duty. Let the parent administer a reproof to them, how soon is one melted into tears of contrition, and of grief for the temporary withdrawal of parental favour, whilst another betrays little, if any, feeling; and we satisfy ourselves with the observation that one child is more susceptible than anothermore sensitive, more tender, or impressible. Now, what is the reason of these differences? Clearly the reason does not reside in any conditions external to the child-or in any in- 
Huences which have been brought to bear upon him-for his education is scarcely begun. His mind is yet almost in its natural state. 'The suggestions of prudence, of decorum, or of policy, do not arise in his untrained mind, and what he betrays is the spontaneous result of his unsophisticated nature. He is the creature of his organisation, and it is to the study of his organisation, therefore, that we must look for the solution to our inquiry for the reason of these differences.

We know very well, and I shall take it for granted that you have no doubt of it, that the brain is the organ in which the intellectunl functions are carricd on-that all the faculties of the intellect reside in the bruin; and that whether the details of phrenology be true or not, it is clear that the various powers of the mind are connected with some portion or other of the great mass of nervous substance rontained within the cavity of the skull, and called the brain; and that the rclative excellence or deficiencs of these: various powers or faculties is in immediate relntion with some condition of size or quality of certain portions of the brain. We cannot measure the exalt relations which subsist between the possession of a particular mental power, and a particular cerebral development; but that some such relation does exist, we cannot entertain a doult. We see that men's heads differ greatly both in size and shape, and we recognise these differences in our every day conversation. i.c. slenk of large hearls, and small heals, of well shaped hear's, and of irregularly shaped heads, and we notice also great dep's 'urtures from a uniform shape in the breadth and height of the forchcad. in the outline of the upper part of the head, and in the rolative bulk of its hiucler part to the fore part; we obst srre some heads to be round, some to be long, some wide, and: some narrow, besides n great multitude of minor differenr. Avs. And, coincidently with these differences of si\%e and st Jape in the heal, we observe differenecs of mental capacity and power characterising their owners. There is no neell to be learned in the details of anatomy, or of phrennlngy, to take cognisance of these relations and harmonies. They are open to the common obscrvation of all intelligent persons. No good observer can mistake the fact, and the rescarches of philosophy confirm it, that our mental faculties, buth as a whole and severally, are directly depentent, for their relutive superiority or feebleness, upon some condition of size or quality in the material uran, the brain, or some of its parts. For the exteut to which persons are prepared to go in reference to the cietails of the application of 1 doctrine like this, grent diversity exists. Whilst some aflirm that they have found the ley to all the varieties of mental constitution, and the nice differences of intellectunl capacity, in the relative development of particular jarts of the cerebral mass, others think that we have only, hitherto, obtained certain broad features of correspondence between organisation and montal manifestation, in the aggregate. Whichever be right, all unite in attributing to the anterior portions of the brain a direct relation with the intelligent principle-with the manifestation of the intellectual faculties. The same kind of reasoning, however, which leads to this conclusion, leads us still further; the same observations which establish a connection hetween the manifestation of intellectual power, and the condition of the physical organ contained within the skull, point also to an intimate relation between some nortion of the same organ, and the manifestation of the emotions, sentiments, instincts, and propensities. If we grant the relation in the one case, we cannot, deny it in the other. Do not all these faculties belong equally to one mind? are they not all equally constituents, inseparably linked together and intertwined, of the one single conscious I? How can we suppose that one part of man's spiritual nature is wedded, by un indissoluble bond, to the conditions of his organisation, whilst another part of it exists in a totully different mode?

The brain, which is the physical medium through which man's intellectual functions are manifested, is equally the medium through which his instinctive and moral faculties operate. When disease invades this essential organ of the intellectual function, when effusion takes place within his skull, and compresses the delicate tissues of his cerebral structure, or when a blow on the head stuns and suspends his mentul fuculties, does any part of his spiritual composition escape the general ruin? Do not his moral and instinetive faculties participate in the wreck and extinction of his intellect? If apoplexy overtake and prostrate his intelligence, dues not his whole mental manifestation lie procumbent in the same annihilation? We cannot separate the two great orders of psychic manifestations from the same boudage and intimate relation to the organic structure. In this respect they must stand or fall together. Fither one order of spiritual faculties is dependent upon structural conditions, or both are independ. ent of it. Analogy and reason both point alike to the inseparable, inevitable association of mind and matter, in every possible phase of its intellectual, moral, or emotional phenomena.

Sir Henry Holland, in speaking of the nhrenologists, says that "they rightly regard it as probable, or even as proved, that there is a certain plurality of parts in the total structure of the brain corresnonding to, and huving connection with, the the different intellectual and moral facultios. The undoubted natural diversity of these faculties makes this probable, seeing that we must regard a certain organisation as ministering in the present life even to the higher porvers of our nature."

Testimony like this is the concurrent language of all rational authors, who have written on the subject at all; and though I wish in the present lecture to deal with the subject in a strictly scientific manner, it seems to me that an unanswerable argu. ment to the same effect is supplied to us by our religion. We find that when disease invades the general structure of the brain, all the faculties, mental, moral, and instinctive, succumb to the devastating plague.

With the inability to reason and to judge, the faculty of dis. tinguishing right from wrong may be lessened or destroyed; the nicety of moral perception may he obscured, the coutrol of the emotions and the instincts may be more or less lost, ana the whole psychical life onervated.

Now, without going into the details of phrenology, it is pretty wcll agreed on all hands, that the functions of the intellect are performed chiefly hy the anterior parts of the brain, thoso parts which are situated just hehind the forehead-a broad and high forehead has heen by miversal consent associated with the possession of great intellectual powers; and a contracted and low foreheal with the opposite condition of mind. Taking this conclusion as indisputable, and benring in mind two otherimportant facts, that the moral and instinctive faculties bear no nccessary relation to the extent or vigour of the intellectual powers; and also that the summit and back part of the head sustain infiuite modifications of form and development, relatirely to the anterior parts, we nre led to assign the upper and hinder parts of the head as the seat of the mural faculties and the passions, just as we assign the forehead as the seat of the intelliret.

"Ihe coronal region of the brain," says George Combe, "is the seat of the moral sentiments, and its size may be estimated by the extent of elevation and expansion of the berd above tho organs of causality in the forehrear and of cautiousness in the millde of the parietal bones. When the whole region of tho brain rising ubove these orrans is shallow and narrow, the moral feelings will be weakly manifested; when high and expnniled, ther will be vigorously displnyed." (Cumbe's System of Phrenology, vol. i, p. 112.)

I shall cnter into no further discussion at present with a view of proving this position. It would lead us bejond the scope of my present argument. But it was necessary to mention it, because it is in such beautiful accordance with the result of our observations in the phenomenn of psychology; and if it be so, it affords so striking a corroboration of the view I am about to lay before you. We do observe, that a man may possess an intellert of one grade, whilst his moral faculties and his in. stinctive propensities may be of a widely different oriler. $\mathrm{He}$ may have a calm and placid temper, or he may be, irritable, ficry, and impetuous; he may be a benevolent man, of he may be a misanthrope; he may be a well-regulated and creditable citizen, or he may be a clrunkard, a swindler, a liar, a thief, or a murderer; he may be any one of these, and in whicherer phuse of character he may display hinself, he may be, independently of that, possessed of the wits of a Sheridan or a Jurke, or he may be as destitute of talent as a Mavius or a Mavius. There is evidently no inseparable or commensurate relation between the one set of faculties and the other. 'The only connection between them is that they exist in the same mind, and are connected with the same organism, and so exert that mutual influence upon each other, and maintain that degree of s!mpathy with each other, which the various members or oryans of the same inilividual system do in all animal constitutions. They are constituents of the same aggregate sys. tem, and therefore cannot be so independent of each other as if they were parts of different individuals.

Horace told us long ago, that if a puinter represented a woman with a horse's neck and a fish's tail, the result would be an unnatural monster at which all the world would laugh; that in the physical world, no such anomaly or incongruity could have a real existence. In the moral world, however, the representa- 
tion would be much less monstrous. Whilst a man's intellectual faculties may be calculated to give him a respectable place in the ranks as a rational being, by his moral faculties he may approach the level of the animals that have no reason. The picture may also be reversed; and these two extremes may meet through every gradation in the relative excellence of the duplicate powers.

Now we have seen that the intellectual faculties may undergo a change from health without very conspicuously implicating the moral powers in the disorder. I do not say that the intellect can be very largely destroyed by disease, and the moral powers of the mind left unimpairel; there is that amount of connection and sympathy between them which involves the one, to a greater or less extent, in any violent injury which may befall the other. But observation shows that the integrity of the intellect can be invaded by disease, whilst the moral powers remain possessed of a large share of soundness, and the residence of the latter faculties in a distinct division or region of the brain, would afford a satisfactory explanation of this phenomenon. Then let me ask, if this be so, can any reason be imagined why the moral powers themselves should not be liable to the invasion of disease, to an equal extent, without involving the intellectual powers? If we grant the localisation of the different orders of faculties in different regions of the brain, and allow that disease may have its principal seat in that part of the brain assigned to the intellectual faculties, what hinders us from the converse conclusion, that the chief seat of the disease may be in that region of the brain which performs the moral and instinctive functions? Nay, I think the inference is inevitable, that such may be the case, and I think further, that unprejudiced observation conclusively establishes the fact that such is the case. Here, then, we get to the rationale of moral insanity, to the very fons et origo of those moral, affective and instinctive perversions which show themselves in such a vast variety of forms, producing eccentricities of character of every conceivable and possible kind, evincing themselves in otherwise unaccountable modes, sometimes leading to unmistakable insanity, and sometimes to such manifestations of character as lay the foundation for legal investigation into the person's accountability, and at others merely occasioning the resemblance to an intractable, vicious, and ill-conditioned mind. Here, however, we have the explanation of all these difficulties. How simple it appears, when thus stated! but how complicated in its practical application. The infinite diversities in the moral character of different individuals, produced by the various degrees of force in the separate faculties relatively to each other, all acted upon by the singularly diversified agencies of outward circumstances, the improving or vitiating influences of education, and of subjective training, result in phenomena so complex, that the satisfactory application of the simplest doctrine is often extremely difficult. The difficulty is also further increased by the two conditions under which moral insanity is exhibited-either as it may be congenital, or as it may supervene in after life.

[To be continued.]

\section{Gunlstomian aldectures:}

\section{os}

\section{DIABETES AND SACCHARINE CONDITIONS OF THE URINE.}

DELIVERED AT THE ROYAL COLLEGE OF PHYSICIANS, FEBRUARY 25TH, 27TH, AND MARCH 4TH, 1857.

By Alfred B. Garrod, M.D., Fellow of the Royal College of Physicians; Professor of Materia Medica, Therapeutics, and Clinical Medicine, at University College; and Physician to the Hospital.

\section{LECTURE III (continued).}

I HAVE been careful to give you the absolute numbers obtained in some of my experiments upon the influence of diet upon the quantity and quality of the urine in cases of diabetes, because I consider the subject one of great importance, especially in reference to the treatment of the disease; and although, I believe, at the present day most practitioners recommend an animal diet to their patients, yet I am sure that many are inclined not to lay sufficient stress upon it. Dr. Prout gives the following as his reasons for not adhering to such a plan chiefly founded, you will observe, upon an hypothesis as to the assimilation of saccharine principles which at present would scarcely be considered as well established. $\mathrm{He}$ remarks: "For some years past, a diet exclusively animal has been much insisted upon. I do not, however, approve of a diet exclusively animal; but consider a certain proportion of furinaceous matters proper. The recommendation of this admixture of farinaceous matters is founded upon a fact apparently well established; viz., that the assimilation of the saccharine principle is one of the last functions which becomes extinct in animals. The proportions of these two forms of aliment must be varied according to the circumstances of the patient, and particularly according to the degree in which he is able to assimilate albuminous, in preference to farinaceous matters-a point not difficult to be determined by a little attention."

Other physicians have supposed that the total abstraction of amylaceous matters may produce a shock on the patient's system.

In opposition to these views, I may remark, first, that patients are able to bear a strictly animal diet, without the production of any shock to the system, or injury to their health; secondly, that those who have had the greatest success in the treatment of these patients have most exclusively adhered to and strongly recommended such a plan; and lastly, that, as most diabetics, even when not partaking of amylaceous matters, still pass sugar in their urine, and as the amount of this substance, together with the diabetic symptoms in many cases, increases in the direct ratio with the quantity of such taken by the individuals, it follows that, in such patients, any amylaceous or saccharine matters in the food do not become assimilated, but act only as irritants, and should therefore be avoided as far as possible.

I have said that, in many cases, the sugar in the urine bears a strict relation to the amount of amylaceous matters in the food. This does not hold good in some, or at least in certain stages of the disease; and I am of opinion that the power of assimilating or converting such principles into fatty or other substances, which $I$ have regarded as existing in the healthy liver but injured or destroyed in diabetes, may be restored, and still the urine may remain saccharine under a rigid animal diet, from the persistence of the over sugar-forming function of the organ. I could bring forward examples illustrating this point, which is one of very considerable importance in the treatment of the disease, as by it we may be safely guided as to the propriety of allowing a return to the use of bread and vegetables.

Then comes the difficulty, How can a strict diet be devised? After a very short time, patients become disgusted with meat, eggs, etc., unless there is some admixture of bread or vegetable matter. Again, it is desirable to have substances more bulky, and containing less nutritive matter than meat, in order to satisfy the appetite; and this applies especially to a disease in which the cravings of hunger are often very great. Many suggestions have been made. M. Bouchardat proposed, some year's since, the use of a species of bread called pain de gluten, or gluten bread, which is made by washing flour in order to deprive it of the chief portion of the starch, and then forming it into bread or cakes. As made in this country, as far as my experience goes, it is not very palatable, and often contains a very considerable proportion of fecula; and, lastly, it is very costly-a most important item in an article of daily consumption. Nany, I find, would much rather simply limit considerably the quantity of amylaceous matters, than take this gluten bread. I have met with some practitioners who have entertained the idea that gluten has peculiar virtues in this disease, and, therefore, that the advantage would be in proportion to the amount taken; but of course this is erroneous, and the pain de gluten is of use only in proportion as it enables the patient to abstain from amylaceous matters. In Paris, gluten is prepared in several forms; much more attention is paid to its manufacture, and a very superior article is produced-one, in fact, by no means unpalatable.

Many other substitutes have been proposed; all, however, with the exception of the one of which I will now speak, have been received with little or no favour, and have either scarcely been employed at all, or have soon fallen into disuse. This substitute for bread-by far the best with which I am acquainted-is made from bran, and has been brought under the notice of the profession by Mr. Camplin, a medical gentleman of this metropolis, who has himself been a sufferer from diabetes for more than twelve years, but who, I am pleased to add, has been enabled to keep himself in good health, and able to undergo the fatigues of an arduous profession to the present time; and this has been due, in his opinion (in which I would fully coincide), to his being able to keep to a rigid diet, during the time that symptoms have required it, by the use of this 